\title{
Role of Ultrasonography (USG) in Female Subfertility
}

\author{
Sujeet Kumar Jain ${ }^{1}$, Rajul Rastogi ${ }^{2}$, Neha $^{3}$, Sushma Rani ${ }^{4}$, Rehana Najam $^{5}$, Shelly Agarwal ${ }^{6}$ \\ ${ }^{1}$ Assistant Professor, Department of Radiodiagnosis, School of Medical Sciences \& Research, Sharda Hospital, Greater Noida, Uttar Pradesh, India, ${ }^{2}$ Associate \\ Professor, Department of Radiodiagnosis, Teerthanker Mahaveer Medical College \& Research Center, Moradabad, Uttar Pradesh, India, ${ }^{3}$ PG Resident, Department \\ of Radiodiagnosis, Teerthanker Mahaveer Medical College \& Research Center, Moradabad, Uttar Pradesh, India, ${ }^{4}$ Senior Resident, Department of Radiodiagnosis, \\ School of Medical Sciences \& Research, Sharda Hospital, Greater Noida, Uttar Pradesh, India. ${ }^{5}$ Professor, Department of Obstetrics \& Gynecology, Teerthanker \\ Mahaveer Medical College \& Research Center, Moradabad, Uttar Pradesh, India, ${ }^{6}$ Associate Professor, Department of Obstetrics \& Gynecology, School of Medical \\ Sciences \& Research, Sharda Hospital, Greater Noida, Uttar Pradesh, India.
}

\section{Abstract}

Background: In modern era of conservative therapies and minimal invasive surgeries, imaging plays an important role in diagnosis, treatment and determination of prognosis of a disease. Role of ultrasonography (USG) in female subfertility has been documented in World Medical literature. Hence, in this study, we aim to determine the accuracy of USG in determining variety of causes of female subfertility using hysterolaparoscopy as a gold standard in our conditions. Subjects and Methods: One hundred and thirty females in reproductive agegroup presenting with primary and secondary subfertility were included in the study. Females with primary amenorrhea were excluded from the study. All patients underwent endovaginal USG (EVS) while Color Doppler Flow Imaging (CDFI) was used whenever indicated. Imaging was done after 8th-10th day of menstrual cycle and a minimum of 3-4 days after complete cessation of menstrual blood flow. Results: USG is very accurate in detecting polycystic ovaries, leiomyoma / adenomyoma, etc with nearly 100\% accuracy while has considerable limitations in tubal disease and in cases of pelvic inflammatory disease (PID) where the accuracy may fall up to 50\%. Conclusion: USG should be first investigation of choice in all patients presenting with subfertility as it is highly accurate in detecting polycystic ovaries, leiomyoma, endometriosis / adenomyosis, endometrial thickening and uterine and ovarian anomalies. Further imaging, should be used reserved tool in patients with complex clinical disease showing unremarkable or non-characteristic USG.

Keywords: Ultrasonography, Fertility.

Corresponding Author: Dr. Rajul Rastogi, Associate Professor, Department of Radiodiagnosis, Teerthanker Mahaveer Medical College \& Research Center, Moradabad, Uttar Pradesh, India.

Received: June 2019

Accepted: June2019

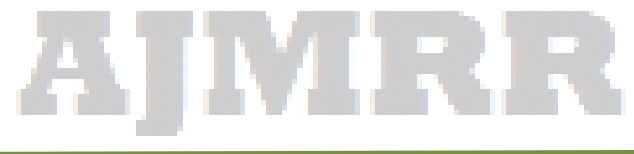

\section{Introduction}

Female subfertility has gained significant attention owing to its rising trend and availability of different modes of its management in modern medicine. As modern medicine is evidence-based and shows inclination towards conservative therapies \& minimal invasive surgeries, imaging assumes pivotal role. Among the imaging armamentarium, ultrasonography (USG) is the key modality utilised in the evaluation of subfertile females. Hence, this study aims to determine the role and accuracy of USG in determining the various causes of subfertility in females using hysterolaparoscopy (HLA) as a gold-standard technique.

\section{Aims of Study}

1. Role of Ultrasonography (USG) in determining causes of subfertility in females

2. Accuracy of USG in detecting various causes of subfertility in females

\section{Subjects and Methods}

A multicentric study involving 130 females in reproductive age-group was performed including primary and secondary subfertility. All the patients included in the study underwent both Transabdominal (TAS) \& Endovaginal (EVS) USG. Imaging was done between $8^{\text {th }}-10^{\text {th }}$ day of menstrual cycle with minimum of 3-4 days after complete stoppage of menstrual blood flow. All the included patients underwent HLA within one week of imaging.

Twenty patients including those with primary amenorrhea or in whom HLA was performed after one week were excluded from the study-group. Hence, a total of 110 patients were included in our study for statistical evaluation.

\section{Observations}

Age of the patients included in the study ranged from 22 years to 38 years.

Out of 110 patients, 66 patients had primary and rest 44 female patients had secondary subfertility.

Patients in the study-group were subcategorised in to those with polycystic ovaries (PCO), tubal disease, pelvic 
inflammatory disease (PID) and miscellaneous (endometrial disease, myometrial leiomyoma / adenomyoma, endometrioma ovary and uterine congenital anomalies) groups.

Patients with multiple findings were included in multiple disease groups viz. fourteen patients were included in both PCO \& PID; ten patients in PCO \& miscellaneous and ten in tubal disease \& PID.

\section{Results}

\section{PCO Group}

The study reveals that USG has $100 \%$ accuracy in detecting polycystic ovaries with positive and negative predictive values of $100 \%$. (Table 1, Figure 1). In our study, out of 54 cases of polycystic ovaries, 34 patients $(63 \%)$ had primary subfertility and 20 patients $(37 \%)$ had secondary subfertility. This shows that PCO is a commoner cause of primary infertility.

\section{Tubal Disease Group}

Patient included in this group are those having salpingitis, hydrosalpinx / pyosalpinx and tubal disease. In our study, out of 20 patients with tubal disease USG could diagnose only 8 patients accurately revealing a low accuracy of $40 \%$ (Table 2, Figure 2). 12 out of 20 patients (60\%) with tubal disease had primary while rest had secondary subfertility suggesting its common prevalence in primary cases.

\section{PID Group}

USG detected less than one-third cases of PID, those that revealed thickened tubes, tubo-ovarian masses, collection in endometrial / pelvic cavity and subendometrial calcification (Table 3 , Figure $3 \& 4$ ). In our study, out of 50 cases of PID, 22 patients $(44 \%)$ had primary while 28 patients $(66 \%)$ had secondary subfertility showing PID as a commoner cause of latter.

The above data also reveals that USG is suboptimal for visualisation of tubes and broad ligament.

\section{Miscellaneous Causes Group (Table 4)}

USG detected uterine anomaly in two patients of our study. One patient had uterus subseptus while other had bicornuate uterus (Figure 5).

USG accuracy was similar to HLA in detection of adenomyosis and leiomyoma (Figure 6).

Endometrial hyperplasia was accurately detected by USG but presence of cystic endometrial hyperplasia could be seen in two patients on USG while infective endometrial thickening was recognised only on HLA in two patients. Endometrial calcification was used as an indirect marker of tubercular endometritis (Figure 7).
Table 2: Distribution of Patients with Tubal Disease

\begin{tabular}{|l|l|l|}
\hline Tubal Status & USG & HLA \\
\hline Dilated & 8 & 14 \\
\hline Damaged & 0 & 6 \\
\hline Total & 8 & 20 \\
\hline
\end{tabular}

Table 3: Distribution of Patients with PID

\begin{tabular}{|l|l|}
\hline USG & HLA \\
\hline 16 & 50 \\
\hline
\end{tabular}

Table 4: Distribution of Patients with Miscellaneous Causes

\begin{tabular}{|l|l|l|}
\hline Factors & USG & HLA \\
\hline Anomaly of tubes Adnexa & 0 & 4 \\
\hline Hypoplasia/ Aplasia of Ovary & 10 & 10 \\
\hline Uterine anomaly & 2 & 2 \\
\hline Endometrioma & 6 & 6 \\
\hline Adenomusis & 2 & 2 \\
\hline Leiomyoma & 12 & 12 \\
\hline Endometrial Hyperplasia & 6 & 6 \\
\hline
\end{tabular}

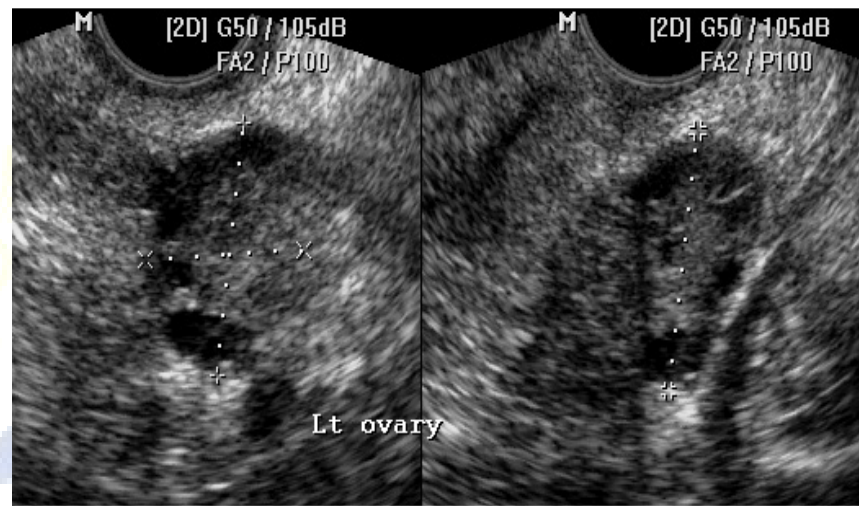

Figure 1: EVS images show a polycystic ovary

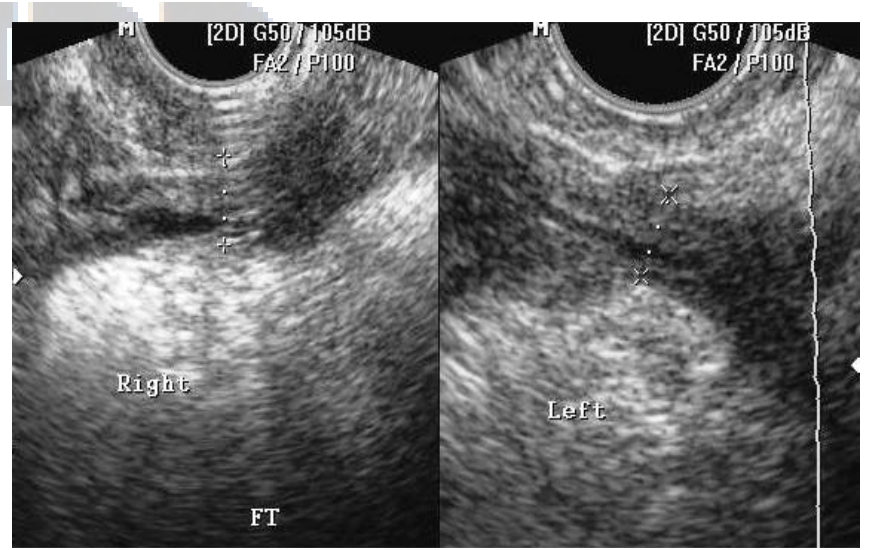

Figure 2: EVS images show thickened \& dilated fallopian tubes in salpingitis 

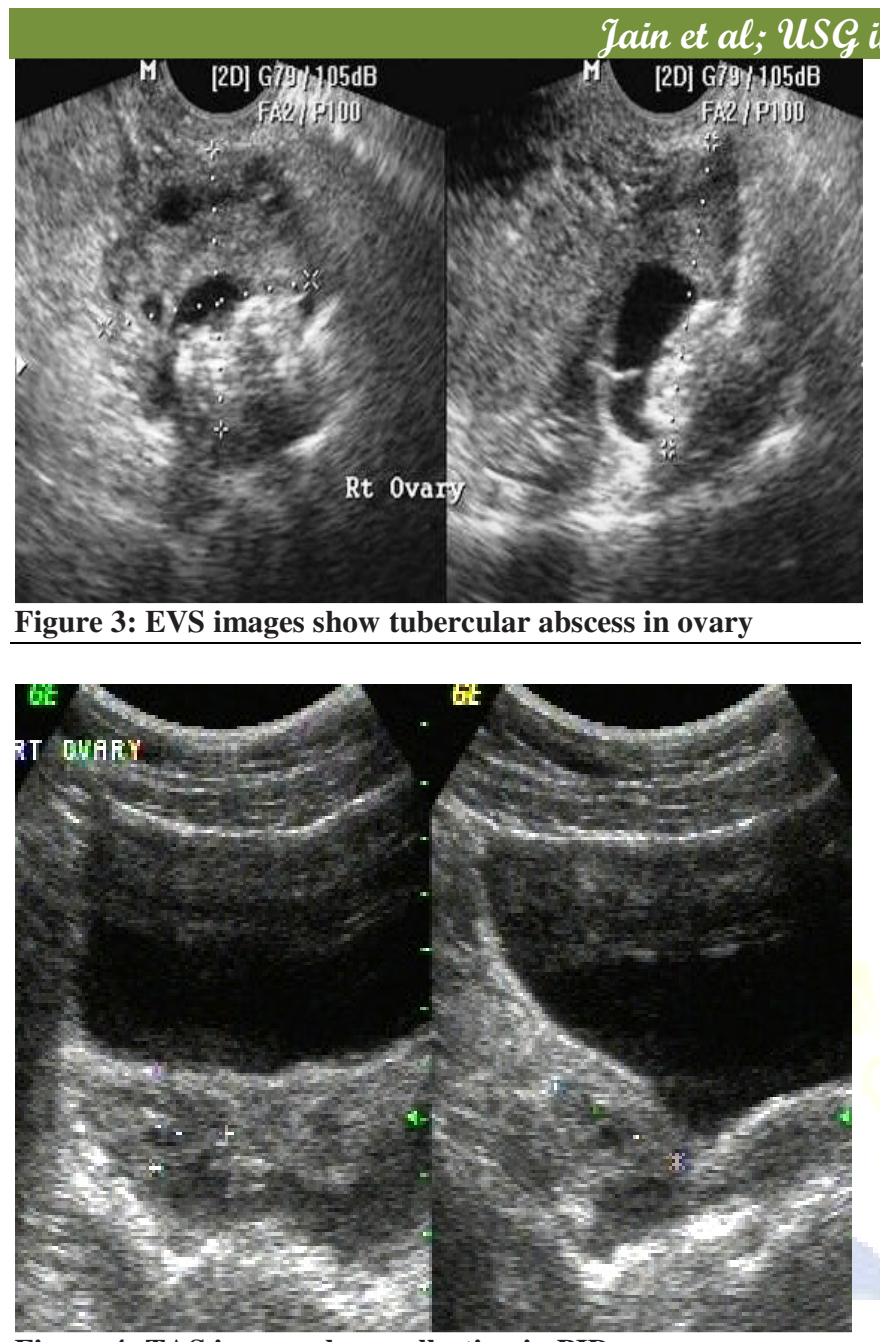

Figure 4: TAS images show collection in PID

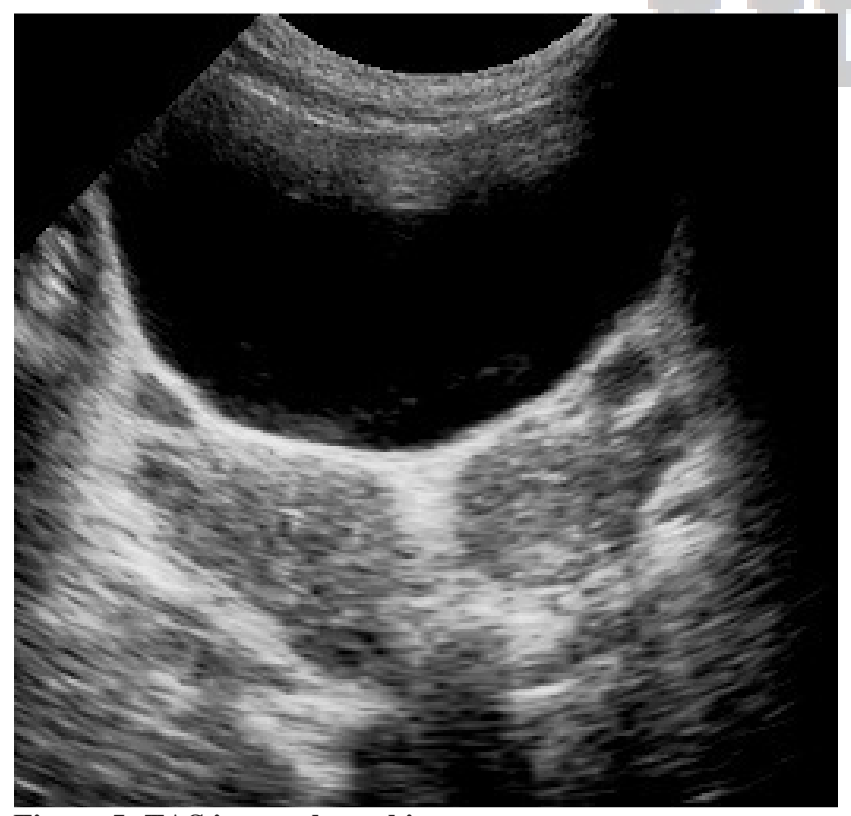

Figure 5: TAS image shows bicornuate uterus

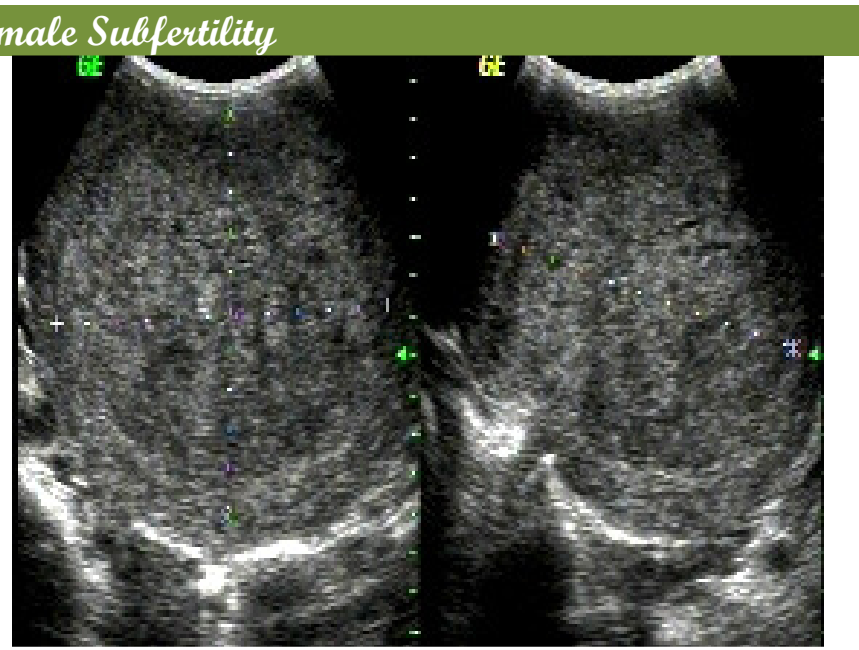

Figure 6: TAS image shows fibroid uterus

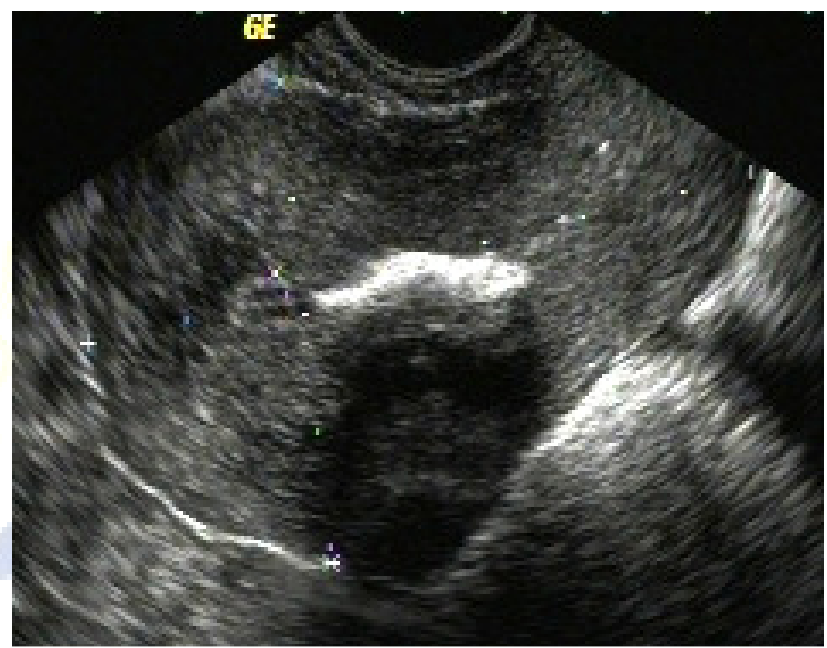

Figure 7: EVS image shows dense endometrial calcification

Discussion

Since female subfertility is quite common and is also a common indication of USG evaluation, hence a study determining the role \& accuracy of USG keeping HLA results as gold-standard was planned by the authors of this study.

Various role of USG in female subfertility has long been described in the medical literature ${ }^{[1]}$ It is the first screening tool guiding the clinician for further course of action. ${ }^{[1,2]}$

USG is shown to be highly accurate in detecting variety of causes of subfertility including endometriosis, adenomyoma, leiomyoma, pelvic inflammatory disease, etc. ${ }^{[3-5]}$ It is not very accurate in detecting tubal disease because of thin tubes and due to lack of soft tissue contrast with adjacent structures.

Very few studies in the medical literature have been done comparing the accuracy of various imaging modalities with that of HLA findings. The results of our study are similar to those described in literature. ${ }^{[4]}$ With the advent of modern USG scanners and increasing competence of imaging specialists in evaluation of subfertile females, this accuracy mar further increase helping in determining the next step of 


\section{Jain et al; USC in Female Sulafertility}

evaluation / management and avoiding unwarranted procedures.

\section{Conclusion}

USG should be standard investigation in all subfertile females as it is highly accurate in detecting majority of the causes of subfertility including polycystic ovaries, leiomyoma, endometriosis / adenomyosis, endometrial thickening and uterine and ovarian anomalies.

Further imaging / invasive procedures, should be used reserved for patients with complex clinical disease showing unremarkable or non-characteristic USG.

\section{References}

1. Hammond CB, Stillman RJ. Infertility and assisted reproduction. In: Scott JR, DiSaia PJ, Hammond CB, Spellacy WN, eds. Danforth's obstetrics and gynecology. 8th ed. Philadelphia, Pa: Lippincott Williams and Wilkins, 1999; 649-667.

2. Rastogi R. Role of imaging in female infertility (Dr. K.M. Rai
Memorial Oration Award). Indian Journal of Radiology and Imaging 2010; 20 (3): 168-173

3. Woodward PJ, Sohaey R, Mezzetti TP, Jr. Endometriosis: radiologic-pathologic correlation. RadioGraphics 2001; 21: 193-216.

4. Rastogi R, Jain S, Mokharia D. Comparative study of Ultrasonography and Magnetic Resonance Imaging in Female Subfertility with Hysterolaparoscopy Correlation. International Journal of Gynecological and Obstetrical Research 2015; 3: 43-48.

5. Dueholm M, Lundorf E, Hansen ES, Ledertoug S, Olsen F. Accuracy of magnetic resonance imaging and transvaginal ultrasonography in the diagnosis, mapping, and measurement of uterine myomas. Am J Obstet Gynecol 2002; 186: 409-415.

Copyright: () the author(s), publisher. Asian Journal of Medical Radiological Research is an Official Publication of "Society for Health Care \& Research Development". It is an open-access article distributed under the terms of the Creative Commons Attribution Non-Commercial License, which permits unrestricted non-commercial use, distribution, and reproduction in any medium, provided the original work is properly cited.

How to cite this article: Jain SK, Rastogi R, Neha, Rani S, Najam R, Agarwal S.Role of Ultrasonography (USG) in Female Subfertility. Asian J. Med.Radiol.Res. 2019;7(1):107-110.

DOI: dx.doi.org/10.21276/ajmrr.2019.7.1.24

Source of Support: Nil, Conflict of Interest: None declared. 